\title{
Predictors of Psychiatric Outpatient Adherence after an Emergency Room Visit for a Suicide Attempt
}

\author{
Jin Shin ${ }^{1}$, Seungbeom Yang ${ }^{1}$, Doo-Heum Park ${ }^{1,2}$, Seung-Ho Ryu ${ }^{1,2}$, \\ Jee Hyun $\mathrm{Ha}^{1,2}$, Jong Won $\mathrm{Kim}^{3}$, and Hong Jun Jeon ${ }^{1 凶}$ \\ ${ }^{1}$ Department of Psychiatry, Konkuk University Medical Center, Seoul, Republic of Korea \\ ${ }^{2}$ Department of Psychiatry, School of Medicine, Konkuk University, Seoul, Republic of Korea \\ ${ }^{3}$ Department of Emergency Medicine, Konkuk University Medical Center, Seoul, Republic of Korea
}

\begin{abstract}
Objective This study aimed to investigate the potential correlation between baseline characteristics of individuals visiting an emergency room for a suicide attempt and subsequent psychiatric outpatient treatment adherence.

Methods Medical records of 525 subjects, who visited an emergency room at a university-affiliated hospital for a suicide attempt between January 2017 and December 2018 were retrospectively reviewed. Potential associations between baseline characteristics and psychiatric outpatient visitation were statistically analyzed.

Results 107 out of 525 individuals (20.4\%) who attempted suicide visited an outpatient clinic after the initial emergency room visit. Several factors (e.g., sober during suicide attempt, college degree, practicing religion, psychiatric treatment history) were significantly related to better psychiatric outpatient follow-up.

Conclusion Several demographic and clinical factors predicted outpatient adherence following a suicide attempt. Therefore, additional attention should be given to suicide attempters who are at the risk of non-adherence by practitioners in the emergency room.
\end{abstract}

Psychiatry Investig 2020;17(9):896-901

Key Words Suicide attempt, Adherence, Emergency room, Outpatient clinic.

\section{INTRODUCTION}

Death by suicide and suicide attempts (SA) are considered serious social problems and critical public health issues. According to WHO statistics, more than 800,000 people die due to suicide every year globally, accounting for $1.4 \%$ of all mortality worldwide. ${ }^{1}$ Death from suicide globally has decreased over the past 2 decades, however, the suicide rate in South Korea is the highest among the OECD countries (24.6 suicide deaths per 100,000 in 2016). ${ }^{2,3}$ Suicide is also the leading cause of death in adolescents and young adults in South Korea. ${ }^{4}$ The economic burden for suicide in South Korea was estimated to be 6,448 billion South Korean Won in 2017, which

Received: April 5, 2020 Revised: May 13, 2020

Accepted: June 25, 2020

$\triangle$ Correspondence: Hong Jun Jeon, MD

Department of Psychiatry, Konkuk University Medical Center, 120-1 Neungdong-ro, Gwangiin-gu, Seoul 05030, Republic of Korea

Tel: +82-2-2030-7699, Fax: +82-2-2030-7399, E-mail: hjjeon@kuh.ac.kr

(a) This is an Open Access article distributed under the terms of the Creative Commons Attribution Non-Commercial License (https://creativecommons.org/licenses/by$\mathrm{nc} / 4.0$ ) which permits unrestricted non-commercial use, distribution, and reproduction in any medium, provided the original work is properly cited. is equivalent to approximately 5.5 billion United States Dollar. ${ }^{5}$

Suicide attempt is known to be an important risk factor for suicide death. ${ }^{67}$ In fact, $10 \%$ of suicide attempts subsequently lead to suicide within 10 years. ${ }^{8}$ In addition, psychiatric disorders are significantly related to suicide death and SA.-11 Therefore, psychiatric evaluation and treatment of subjects who attempt suicide is very important in preventing suicide death. ${ }^{12,13}$ Many individuals who attempt suicide visit the emergency room (ER) seeking for primary treatment, and concomitant psychiatric intervention is highly important to prevent further suicide attempts. However, the actual follow-up rate for psychiatric visit after ER discharge is relatively low. ${ }^{14-16}$ So far, few studies have evaluated the psychiatric adherence of individuals attempting suicide, therefore, this study aimed to investigate factors affecting outpatient follow-up of patients who visited the ER for SA.

\section{METHODS}

\section{Study design and participants}

The study is a retrospective study and data were collected 
using medical record review. Between January 2017 and December 2018, all patients who visited the ER at the Konkuk University Medical Center, a tertiary hospital located at Seoul, Korea for SA were included. All the patients who visited the ER for suicide attempts were seen by psychiatric residents and an outpatient appointment was made in all cases based on the policy of the hospital. The treatment adherence was defined as visiting the psychiatric outpatient clinic of Konkuk Medical Center at least once after discharge from the ER. In case of subjects who were admitted to medical or psychiatric ward directly from ER, visiting psychiatric outpatient clinic after discharge from the ward was regarded as treatment adherence. Subjects who never visited the psychiatric outpatient clinic after discharge were assigned to the non-adherent group.

\section{Measures}

Sociodemographic information (i.e., gender, age, education, type of health insurance, religion, and household members) and clinical data (i.e., types of SA, number of previous SA, previous psychiatric admission or treatment history, psychiatric family history and primary psychiatric diagnosis made by psychiatric residents through unstructured interview) were obtained. Information related to ER visit included: 1) if patients visited the ER on a weekday or a weekend, 2) if patients came to the ER by themselves or were brought by someone else, 3) whether anyone accompanied the individual who attempted suicide when they visited ER or not and 4) whether the patients was in a drunken state during SA or sober. Additionally, whether or not the patient needed medical or surgical attention in the ER because of the SA was captured. This study was approved by the Institutional Review Board of the Konkuk University Medical Center (KUMC 201910026).

\section{Statistical analysis}

The student's t-test and chi-square test were used to compare variables between the adherent and non-adherent groups. Multivariate logistic regression analysis was used to examine the relation of psychiatric outpatient follow-up and patient characteristics. Variables that showed significant difference in the t-test or chi-square test (college graduation, religion, alcohol intake during SA, psychiatric treatment history, previous SA history and psychiatric admission history) were entered as independent variables predicting outpatient clinic visit. A p-value less than 0.05 was considered statistically significant. All statistical analyses were performed using SPSS version 17 (SPSS, Inc., Chicago, IL, USA).

\section{RESULTS}

Among the 525 patients who visited our ER for a SA during the period. Eighty-four \% of the patient were discharged from ER and $16 \%$ were hospitalized $(6.1 \%$ at psychiatric ward and $9.9 \%$ at general ward). A total of 107 (20.4\%) showed-up at the outpatient clinic after discharge from ER or ward.

Demographic and clinical characteristics were compared between groups (Table 1). There was no statistically significant difference between adherent and non-adherent groups in gender, age, type of health insurance, living with family members, spontaneity of ER visit, company at ER, type of SA, other department referral, and medical history. However, there were more college graduates in the adherent group compared with the non-adherent group ( $47.5 \%$ vs. $29.5 \%$, respectively; $\mathrm{p}=0.001$ ). The adherent group was more likely to have religion compared with the non-adherent group $(27.1 \%$ vs. $12.9 \%$, respectively; $\mathrm{p}<0.001)$. The non-adherent group tended to attempt suicide while they were drunken ( $44.7 \%$ vs. $29.9 \%$, respectively; $\mathrm{p}=0.006$ ). The adherent group was more likely have a history of psychiatric treatment (64.5\% vs. $47.8 \%$, respectively; $\mathrm{p}=0.002)$, history of psychiatry admission ( $19.6 \%$ vs. $12.0 \%$, respectively; $\mathrm{p}=0.039)$, history of previous SA $(51.4 \%$ vs. $35.6 \%$, respectively; $\mathrm{p}=0.003$ ) and family history of psychiatric treatment $(24.3 \%$ vs. $13.2 \%$, respectively; $p=0.004)$. Higher proportion of patients who were admitted directly from the ER showed up in the outpatient clinic than patient who were discharged from the ER $(p<0.001)$, however, there were no significant difference according to spontaneity of the admission $(\mathrm{p}=0.192)$. There were significant differences in terms of psychiatric diagnosis and number of previous SA between the groups.

In the multivariate logistic regression analyses (Table 2), drunken state during SA was a risk factor of psychiatric outpatient follow-up loss (odd ratio=0.566, $\mathrm{p}=0.026$ ). College graduation (odd ratio $=2.334, \mathrm{p}=0.001$ ), having a religion (odd ratio $=1.819, \mathrm{p}=0.033$ ) and psychiatric treatment history (odd ratio $=1.717, \mathrm{p}=0.032$ ) were protective factors of psychiatric outpatient treatment adherence. Psychiatric family history was not significantly different in multivariate logistic regression analysis (odd $=1.706, \mathrm{p}=0.067$ ).

\section{DISCUSSION}

Among the 525 subjects who visited our ER after SA included in this study, 20.4\% (107) visited a psychiatry outpatient department after discharge. In our study, factors demonstrated to predict psychiatric outpatient follow up after SA were psychiatric treatment history, drunken state during $\mathrm{SA}$, practicing religion and a college degree. 
Table 1. Baseline demographics and clinical background by group

\begin{tabular}{|c|c|c|c|c|}
\hline & $\begin{array}{l}\text { Adherent group } \\
(\mathrm{N}=107,20.4 \%)\end{array}$ & $\begin{array}{c}\text { Non-adherent group } \\
(\mathrm{N}=418,79.6 \%)\end{array}$ & $\begin{array}{c}\text { Total } \\
(\mathrm{N}=525)\end{array}$ & p-value \\
\hline \multicolumn{5}{|l|}{ Sociodemographic information } \\
\hline Gender, female & $77(72)$ & $283(67.7)$ & $360(68.6)$ & 0.397 \\
\hline Age, mean & 36.77 & 36.93 & 36.90 & 0.928 \\
\hline College graduation & & & & $0.001^{*}$ \\
\hline No & $53(52.5)$ & $220(70.5)$ & $273(66.1)$ & \\
\hline Yes & $48(47.5)$ & $92(29.5)$ & $140(33.9)$ & \\
\hline Unknown & 6 & 106 & 112 & \\
\hline Medicaid beneficiary & & & & 0.117 \\
\hline Yes & $4(3.7)$ & $34(8.1)$ & $38(7.2)$ & \\
\hline No & $103(96.3)$ & $384(91.9)$ & $487(92.8)$ & \\
\hline Religion & $29(27.1)$ & $54(12.9)$ & $83(15.8)$ & $<0.001^{*}$ \\
\hline Family members living with & & & & 0.120 \\
\hline Presence & $85(79.4)$ & $293(72.0)$ & $378(73.5)$ & \\
\hline Absence & $22(20.6)$ & $114(28.0)$ & $136(26.5)$ & \\
\hline Unknown & 0 & 11 & 11 & \\
\hline \multicolumn{5}{|l|}{ ER information } \\
\hline Visit day & & & & 0.512 \\
\hline Weekday & $76(71.0)$ & $310(74.2)$ & $386(73.5)$ & \\
\hline Weekend or holidays & $31(29.0)$ & $108(25.8)$ & $139(26.5)$ & \\
\hline Spontaneity & & & & 0.360 \\
\hline By oneself & $8(7.5)$ & $48(11.5)$ & $56(10.7)$ & \\
\hline By police/rescue team & $10(9.3)$ & $48(11.5)$ & $58(11)$ & \\
\hline By family/friends & $89(83.2)$ & $322(77.0)$ & $411(78.3)$ & \\
\hline Company at ER & & & & 0.055 \\
\hline Yes & $104(97.2)$ & $384(91.9)$ & $488(93.0)$ & \\
\hline No & $3(2.8)$ & $34(8.1)$ & $37(7.0)$ & \\
\hline Disposition after ER & & & & $<0.001^{*}$ \\
\hline Discharge & $65(60.7)$ & $379(90.7)$ & $444(84.6)$ & \\
\hline Admission to psychiatry & $27(25.2)$ & $2(0.5)$ & $29(5.5)$ & \\
\hline Admission to other department & $15(14.0)$ & $37(8.9)$ & $52(9.9)$ & \\
\hline Spontaneity of psychiatric admission & & & & 0.192 \\
\hline Voluntary admission & $16(59.3)$ & $0(0.0)$ & $16(55.2)$ & \\
\hline Involuntary admission & $11(40.7)$ & $2(100)$ & $13(44.8)$ & \\
\hline \multicolumn{5}{|l|}{ Medical evaluation } \\
\hline Medical consultations in ER & $46(43.0)$ & $160(38.3)$ & $206(39.3)$ & 0.383 \\
\hline Medical history & & & & 0.680 \\
\hline Absence & $89(83.2)$ & $354(84.7)$ & $443(84.4)$ & \\
\hline 1 disease under treatment & $8(7.5)$ & $35(8.4)$ & $43(8.2)$ & \\
\hline$\geq 2$ disease under treatment & $10(9.3)$ & $29(6.9)$ & $39(7.4)$ & \\
\hline \multicolumn{5}{|l|}{ Psychiatric evaluation } \\
\hline Type of SA & & & & 0.221 \\
\hline Drug intoxication & $61(57.0)$ & $272(65.1)$ & $333(63.4)$ & \\
\hline Superficial cutting & $15(14.0)$ & $52(12.4)$ & $67(12.8)$ & \\
\hline
\end{tabular}


Table 1. Baseline demographics and clinical background by group (continued)

\begin{tabular}{|c|c|c|c|c|}
\hline & $\begin{array}{l}\text { Adherent group } \\
(\mathrm{N}=107,20.4 \%)\end{array}$ & $\begin{array}{l}\text { Non-adherent group } \\
(\mathrm{N}=418,79.6 \%)\end{array}$ & $\begin{array}{c}\text { Total } \\
(\mathrm{N}=525)\end{array}$ & p-value \\
\hline Stab wound & $12(11.2)$ & $48(6.5)$ & $60(11.4)$ & \\
\hline Fall down & $8(7.5)$ & $27(6.5)$ & $35(6.7)$ & \\
\hline Hanging & $9(8.4)$ & $13(3.1)$ & $22(4.2)$ & \\
\hline Gas inhalation & $2(1.9)$ & $6(1.4)$ & $8(1.5)$ & \\
\hline Alcohol intake during SA & & & & $0.006^{*}$ \\
\hline Alcohol intoxicated & $32(29.9)$ & $187(44.7)$ & $219(41.7)$ & \\
\hline Sober & $75(70.1)$ & $231(55.3)$ & $306(58.3)$ & \\
\hline Psychiatric treatment history & $69(64.5)$ & $200(47.8)$ & $269(51.2)$ & $0.002^{*}$ \\
\hline Previous SA history & $55(51.4)$ & $149(35.6)$ & $204(38.9)$ & $0.003^{*}$ \\
\hline Number of previous SA & & & & $0.023^{*}$ \\
\hline 0 & $52(48.6)$ & $271(64.8)$ & $323(61.5)$ & \\
\hline 1 & $24(22.4)$ & $71(17.0)$ & $95(18.1)$ & \\
\hline$\geq 2$ and $\leq 5$ & $11(10.3)$ & $32(7.7)$ & $43(8.2)$ & \\
\hline$\geq 6$ and $\leq 10$ & $2(1.9)$ & $2(0.5)$ & $4(0.8)$ & \\
\hline$\geq 11$ & $18(16.8)$ & $42(10.0)$ & $60(11.4)$ & \\
\hline Psychiatric admission history & $21(19.6)$ & $50(12.0)$ & $71(13.5)$ & $0.039^{*}$ \\
\hline Psychiatric diagnosis & & & & $<0.001^{*}$ \\
\hline Unipolar depression & $86(80.4)$ & $385(92.1)$ & $471(89.7)$ & \\
\hline Bipolar disorder & $10(9.3)$ & $14(3.3)$ & $24(4.6)$ & \\
\hline Anxiety disorder & $3(2.8)$ & $0(0)$ & $3(0.6)$ & \\
\hline Psychotic disorder & $5(4.7)$ & $10(2.4)$ & $15(2.9)$ & \\
\hline Other psychiatric disorders & $3(2.8)$ & $9(2.2)$ & $12(2.3)$ & \\
\hline Psychiatric family history & $26(24.3)$ & $55(13.2)$ & $81(15.4)$ & $0.004^{*}$ \\
\hline
\end{tabular}

*statistically significant $(\mathrm{p}<0.05)$. ER: emergency room, SA: suicide attempt

Table 2. Multivariate logistic regression analysis for prediction of psychiatric outpatient follow up

\begin{tabular}{lccc}
\hline \multirow{2}{*}{\multicolumn{1}{c}{ Variables }} & \multicolumn{3}{c}{$\begin{array}{c}\text { Multivariate logistic regression, } \\
\text { Nagelkerke } \mathrm{R}^{2}=0.111\end{array}$} \\
\cline { 2 - 5 } & $\begin{array}{c}\text { Odd } \\
\text { ratio }\end{array}$ & p-value & $95 \% \mathrm{CI}$ \\
\hline Alcohol intake during SA & 0.566 & $0.026^{*}$ & $0.342-0.935$ \\
Experience of university education & 2.334 & $0.001^{*}$ & $1.446-3.768$ \\
Religion & 1.819 & $0.033^{*}$ & $1.050-3.153$ \\
Psychiatric treatment history & 1.717 & $0.032^{*}$ & $1.048-2.811$ \\
Psychiatric family history & 1.706 & 0.067 & $0.963-3.023$ \\
\hline
\end{tabular}

*statistically significant $(\mathrm{p}<0.05)$. SA: suicide attempt

Subjects who have experience with psychiatric treatment tend to be more adherent to psychiatric outpatient follow-up compared with those who have no psychiatric treatment experience. Results of previous studies are consistent with this study. ${ }^{17-20}$ Suokas et al. ${ }^{18}$ reported that patients receiving prior psychiatric treatment were referred more often for psychiatric consultation in the ER. Cremniter et al. ${ }^{19}$ reported that a history of psychiatric treatment is the best predictor of compliance in psychiatric emergency patients and emphasized that non-compliance in the ER was the most important predictor of deterioration. This result implies that subjective experience and attitude formed by previous psychiatric treatment could influence psychiatric adherence.

Previous studies have demonstrated inconclusive results on the relationship between past SA and psychiatric adherence. Lee et al. ${ }^{21}$ reported that the compliant group had more previous SAs compared to the non-compliant group, however, these results were not clinically significant. A study by Costemale-Lacoste et al..$^{14}$ also demonstrated similar results. In their multi-site prospective study, they investigated factors that affect outpatient treatment engagement after a SA and reported that a previous SA did not predict 1-month and 3-month follow-up. Here, it was demonstrated that patients who had attempted suicide in the past showed better outpatient treatment adherence; two possible explanations exist for this observation. First, patients who have attempted suicide multiple times are more likely to have more serious un- 
derlying psychiatric illnesses compared with patients who did not and are, therefore more likely to seek treatment. Alternatively, there could be a link between a previous SA and compliance related to the patient's satisfaction with previous medical treatment. It has been suggested that patient's satisfaction with medical service is highly important in terms of compliance in psychiatric ${ }^{22}$ and medical patients. ${ }^{23} \mathrm{~A}$ patient who attempted suicide may have experienced various medical services and the variety of degree of their subjective satisfaction might have contributed to the inconclusive results of previous studies. However, since we have not investigated detailed past psychiatric treatment experiences of patients who attempted suicide, it was not possible to demonstrate a relationship between previous treatment experiences and psychiatric compliance.

It is well known that problematic alcohol use is a risk factor for suicide death and SA. ${ }^{24-26}$ These include disinhibition, impulsivity, poor judgment, and underlying personality disorder in patients with problematic alcohol drinking. ${ }^{27-32}$ In addition, alcohol use is also associated with low treatment adherence, which is related to the fluctuating nature of the personality of alcohol-dependent patients. ${ }^{33}$ This study also suggests that patients who were drunken during their SA had low outpatient adherence, and that these patients required further intervention. This result is consistent with those of many previous studies. ${ }^{16,34-37}$ SA patient who attempted suicide while drunken may have poor insight on their action and may not follow medical advice provided.

To the best of our knowledge, this is the first study to report that religion is associated with improved outpatient adherence in individuals attempting suicide. In previous studies, religion has also been known to act as a protective factor in various psychiatric conditions including depression, alcohol use disorder, PTSD and suicide attempts. ${ }^{38-41}$ In addition, religion is related with increased resilience (i.e., one's ability to overcome adversities or trauma). ${ }^{42}$ Possible mechanisms between religion and mental health include greater feelings of self-efficacy and self-regulation, behavioral restraint and enhanced social support. ${ }^{41}$

College graduation is also a predictor of psychiatric followup. Previous studies have reported that subjects with higher levels of education tend to use mental health care services more frequently compared with a lower level of education group. ${ }^{43,44}$ Costemale-Lacoste et al. ${ }^{14}$ also reported that postgraduate studies predict better specialized out-patient treatment engagement at a 1-month follow up. Individuals achieving higher levels of education may be more informed about psychiatric illness, treatment and resources. Furthermore, higher education is related to higher socio-economic status, another crucial factor impacting medical treatment in most countries.
There are some limitations of our study, including the retrospective nature which does not guarantee that potential confounding factors that could influence results are eliminated. Additionally, the reasons why some patients attended psychiatric outpatient follow-ups and some others did not were not explored. There is a possibility that patients who received treatment after suicide attempts in the psychiatric clinic other than Konkuk Medical Center were regarded as non-adherent subjects. Finally, multiple definitions of treatment adherence exist; here it was defined as one visit to the outpatient clinic, therefore information on long-term follow-up was not assessed. Evaluation of follow-up duration might be a more accurate way to evaluate treatment adherence.

However, while previous studies have focused on the certain proportion of suicide attempters, we could collect the data from all patients who attempted suicide and visited an ER at a tertiary general hospital for relatively long period. Therefore, we could identify factors which are related to subsequent outpatient treatment adherence and firstly report that religion is positively related to treatment adherence in suicide attempters. Based on our findings, clinicians who encounter suicide attempters in ER may adopt specific strategies $^{45,46}$ designed to improve treatment adherence for those who are at the risk of non-adherence. Further studies that specifically assess factors influencing a patient's treatment followup are warranted as they may further improve compliance for care provided after a suicide attempt.

\section{Acknowledgments}

None.

\section{Conflicts of Interest}

The authors have no potential conflicts of interest to disclose.

\section{Author Contributions}

Conceptualization: Hong Jun Jeon. Data curation: Seungbeom Yang, Jong Won Kim. Formal analysis: Hong Jun Jeon. Methodology: Hong Jun Jeon. Project administration: Doo-Heum Park. Supervision: Jee Hyun Ha, Seung-Ho Ryu. Writing_original draft: Jin Shin, Hong Jun Jeon. Writing_review \& editing: Jin Shin, Hong Jun Jeon.

\section{ORCID iDs}

\section{Jin Shin}

Seungbeom Yang

Doo-Heum Park

Seung-Ho Ryu

Jee Hyun Ha

Jong Won Kim

Hong Jun Jeon

https://orcid.org/0000-0001-5331-6728

https://orcid.org/0000-0002-7783-309X

https://orcid.org/0000-0002-4833-5366

https://orcid.org/0000-0001-8057-8723

https://orcid.org/0000-0002-0973-1139

https://orcid.org/0000-0002-4844-1572

https://orcid.org/0000-0002-0260-0494

\section{REFERENCES}

1. World Health Statistics. Monitoring Health for the SDGs Sustainable Development Goals. Geneva: World Health Organization; 2016.

2. OECD. Suicide rates. Available at: https://data.oecd.org/healthstat/suicide-rates.htm. Accessed May 11, 2020.

3. Naghavi M. Global, regional, and national burden of suicide mortality 
1990 to 2016: systematic analysis for the Global Burden of Disease Study 2016. BMJ 2019;364:194

4. Statistics Korea. Cause of Death Statistics 2018. Daejeon: Statistics Korea; 2019.

5. Hyun KR, Choi KC, Lee SM, Lee SY. Analysis of Socio-economic Costs of Major Diseases for Health Policy. Wonju: Health Insurance Policy Institute, National Health Insurance Service; 2017.

6. Finkelstein Y, Macdonald EM, Hollands S, Sivilotti ML, Hutson JR, Mamdani MM, et al. Risk of suicide following deliberate self-poisoning. JAMA Psychiatry 2015; 2:570-575.

7. Leon AC, Friedman RA, Sweeney JA, Brown RP, Mann JJ. Statistical issues in the identification of risk factors for suicidal behavior: the application of survival analysis. Psychiatry Res 1990;31:99-108.

8. Weiss JM, Scott KF Jr. Suicide attempters ten years later. Compr Psychiatry 1974;15:165-171.

9. Mortensen PB, Agerbo E, Erikson T, Qin P, Westergaard-Nielsen N. Psychiatric illness and risk factors for suicide in Denmark. Lancet 2000; 355:9-12.

10. Guze SB, Robins E. Suicide and primary affective disorders. Br J Psychiatry 1970;117:437-438.

11. Inskip HM, Harris EC, Barraclough B. Lifetime risk of suicide for affective disorder, alcoholism and schizophrenia. Br J Psychiatry 1998;172: 35-37.

12. O'Leary D, Paykel E, Todd C, Vardulaki K. Suicide in primary affective disorders revisited: a systematic review by treatment era. J Clin Psychiatry 2001;62:804-811.

13. Zalsman G, Hawton K, Wasserman D, van Heeringen K, Arensman E, Sarchiapone M, et al. Suicide prevention strategies revisited: 10-year systematic review. Lancet Psychiatry 2016;3:646-659.

14. Costemale-Lacoste JF, Balaguer E, Boniface B, Ivascu EB, Bernardini $\mathrm{C}$, Metton JP, et al. Outpatient treatment engagement after suicidal attempt: a multisite prospective study. Psychiatry Res 2017;258:21-23.

15. Nordentoft M, Sogaard M. Registration, psychiatric evaluation and adherence to psychiatric treatment after suicide attempt. Nord J Psychiatry 2005;59:213-216.

16. Granboulan V, Roudot-Thoraval F, Lemerle S, Alvin P. Predictive factors of post-discharge follow-up care among adolescent suicide attempters. Acta Psychiatr Scand 2001;104:31-36.

17. Lin CJ, Lu HC, Sun FJ, Fang CK, Wu SI, Liu SI. The characteristics, management, and aftercare of patients with suicide attempts who attended the emergency department of a general hospital in northern Taiwan. J Chin Med Assoc 2014;77:317-324.

18. Suokas J, Lonnqvist J. Selection of patients who attempted suicide for psychiatric consultation. Acta Psychiatr Scand 1991;83:179-182.

19. Cremniter D, Payan C, Meidinger A, Batista G, Fermanian J. Predictors of short-term deterioration and compliance in psychiatric emergency patients: a prospective study of 457 patients referred to the emergency room of a general hospital. Psychiatry Res 2001;104:49-59.

20. Lim MH. A psychiatric emergency clinic: a study of attendances over six months. Br J Psychiatry 1983;143:460-466.

21. Lee MJ, Shin CJ, Lee SI, Son JW, Kim S, Ju G, et al. Factors associated with outpatient treatment compliance of the suicide attempter visiting emergency center. J Korean Soc Bio Ther Psychiatry 2017;23:190-198.

22. Gray MJ, Elhai JD, Frueh BC. Enhancing patient satisfaction and increasing treatment compliance: patient education as a fundamental component of PTSD treatment. Psychiatr Q 2004;75:321-332.

23. Renzi C, Picardi A, Abeni D, Agostini E, Baliva G, Pasquini P, et al. Association of dissatisfaction with care and psychiatric morbidity with poor treatment compliance. Arch Dermatol 2002;138:337-342.

24. Darvishi N, Farhadi M, Haghtalab T, Poorolajal J. Alcohol-related risk of suicidal ideation, suicide attempt, and completed suicide: a meta-analysis. PLoS One 2015;10:e0126870.

25. Jeon HJ, Lee JY, Lee YM, Hong JP, Won SH, Cho SJ, et al. Lifetime prevalence and correlates of suicidal ideation, plan, and single and multiple attempts in a Korean nationwide study. J Nerv Ment Dis 2010;198:643646.
26. Berglund M, Ojehagen A. The influence of alcohol drinking and alcohol use disorders on psychiatric disorders and suicidal behavior. Alcohol Clin Exp Res 1998;22:333S-345S.

27. Cherpitel CJ, Borges GL, Wilcox HC. Acute alcohol use and suicidal behavior: a review of the literature. Alcohol Clin Exp Res 2004;28:18S$28 \mathrm{~S}$.

28. Kresnow M, Powell KE, Webb KB, Mercy JA, Potter LB, Simon TA, et al. Assigning time-linked exposure status to controls in unmatched case-control studies: alcohol use and nearly lethal suicide attempts. Stat Med 2001;20:1479-1485.

29. Hufford MR. Alcohol and suicidal behavior. Clin Psychol Rev 2001;21: 797-811.

30. Preuss UW, Koller G, Barnow S, Eikmeier M, Soyka M. Suicidal behavior in alcohol-dependent subjects: the role of personality disorders. Alcohol Clin Exp Res 2006;30:866-877.

31. Newton-Howes G, Foulds J. Personality disorder and alcohol use disorder: an overview. Psychopathology 2018;51:130-136.

32. Choi KW, Na EJ, Hong JP, Cho MJ, Fava M, Mischoulon D, et al. Alcohol-induced disinhibition is associated with impulsivity, depression, and suicide attempt: a nationwide community sample of Korean adults. J Affect Disord 2018;227:323-329.

33. Serebro B. Compliance in the treatment of alcohol-dependent individuals (alcoholics). J Int Med Res 1979;7:165-167.

34. Suokas J, Lonnqvist J. Evaluation of attempted suicides: a comparative study of staff in a general hospital and consulting staff in a psychiatric hospital. Crisis 1989;10:123-131.

35. Compton MT, Rudisch BE, Weiss PS, West JC, Kaslow NJ. Predictors of psychiatrist-reported treatment-compliance problems among patients in routine U.S. psychiatric care. Psychiatry Res 2005;137:29-36.

36. Kwon JW, Ko YH, Han CS, Lee MS, Yoon HK, Lee H. Psychosocial characteristics and factors associated with referral to psychiatric care in the suicide attempters visiting emergency center. Korean J Psychosom Med 2013;21:106-113.

37. Jin W, Choi WJ, Yoon JH, Cho HS, Kim SJ, Lee E, et al. Associated factors of psychiatric follow-up after emergency care in suicide attempters. Mood Emot 2013;11:130-137.

38. Rasic D, Robinson JA, Bolton J, Bienvenu OJ, Sareen J. Longitudinal relationships of religious worship attendance and spirituality with major depression, anxiety disorders, and suicidal ideation and attempts: findings from the Baltimore epidemiologic catchment area study. J Psychiatr Res 2011;45:848-854.

39. Koenig HG. Research on religion, spirituality, and mental health: a review. Can J Psychiatry 2009;54:283-291.

40. Lawrence RE, Oquendo MA, Stanley B. Religion and suicide risk: a systematic review. Arch Suicide Res 2016;20:1-21.

41. Sharma V, Marin DB, Koenig HK, Feder A, Iacoviello BM, Southwick SM, et al. Religion, spirituality, and mental health of U.S. military veterans: Results from the National Health and Resilience in Veterans Study. J Affect Disord 2017;217:197-204.

42. Brewer-Smyth K, Koenig HG. Could spirituality and religion promote stress resilience in survivors of childhood trauma? Issues Ment Health Nurs 2014;35:251-256.

43. Have M, Oldehinkel A, Vollebergh W, Ormel J. Does educational background explain inequalities in care service use for mental health problems in the Dutch general population? Acta Psychiatr Scand 2003; 107:178-187.

44. Steele LS, Glazier RH, Agha M, Moineddin R. The gatekeeper system and disparities in use of psychiatric care by neighbourhood education level: results of a nine-year cohort study in Toronto. Healthc Policy 2009; 4:e133-e150.

45. Spirito A, Boergers J, Donaldson D, Bishop D, Lewander W. An intervention trial to improve adherence to community treatment by adolescents after a suicide attempt. J Am Acad Child Adolesc Psychiatry 2002; 41:435-442.

46. Luxton DD, June JD, Comtois KA. Can postdischarge follow-up contacts prevent suicide and suicidal behavior? Crisis 2013;34:32-41. 